\title{
Erratum
}

In the article below (Volume 154, Number 1, pp 35-46) an unfortunate mix-up with regard to the figures occurred on pages 40 and 41 . One figure was duplicated and one completely omitted. Therefore, pages 40 and 41 are reprinted as they should have appeared. We apologise for this error.

In addition, the present address of the primary author was inadvertently omitted on the title page. Please address all offprint requests to: Helve Hõbe, Department of Biology, University of Calgary, Alberta, Canada, T2N 1N4.

\section{Mechanisms of acid-base and ionoregulation in white suckers (Catostomus commersoni) in natural soft water}

\section{Acute exposure to low ambient pH}

Helve Hõbe, Chris M. Wood, and Brian R. McMahon

Harkness Laboratory of Fisheries Research, Ontario Ministry of Natural Resources, Box 110, Whitney, Ontario, Canada K0J 2M0, Department of Biology, McMaster University, Hamilton, Ontario, Canada L8S 4K1, and Department of Biology, University of Calgary, Calgary, Alberta, Canada T2NIN4 